NBER WORKING PAPER SERIES

\title{
ACCOUNTING FOR THE IMPACT OF MEDICAID ON CHILD POVERTY
}

\author{
Sanders Korenman \\ Dahlia K. Remler \\ Rosemary T. Hyson \\ Working Paper 25973 \\ http://www.nber.org/papers/w25973 \\ NATIONAL BUREAU OF ECONOMIC RESEARCH \\ 1050 Massachusetts Avenue \\ Cambridge, MA 02138 \\ June 2019
}

This paper was originally prepared as a background paper commissioned by the National Academy of Sciences for its Committee on Building an Agenda to Reduce the Number of Children in Poverty by Half in 10 Years. The paper was submitted in October 2017 and embargoed until the release of the Committee's report, A Roadmap to Reducing Child Poverty, 2019. DOI https://doi.org/10.17226/25246. This version includes minor clarifications and a correction. It appears in the NBER working paper series with permission from the National Academy of Sciences, Courtesy of the National Academies Press, Washington, D.C. We thank members of the Committee for their questions and suggestions and the Russell Sage Foundation for support for the further development of the Health Inclusive Poverty Measure. The views expressed herein are those of the authors and do not necessarily reflect the views of the National Bureau of Economic Research.

NBER working papers are circulated for discussion and comment purposes. They have not been peer-reviewed or been subject to the review by the NBER Board of Directors that accompanies official NBER publications.

(C) 2019 National Academy of Sciences, circulated with permission. All rights reserved. Short sections of text, not to exceed two paragraphs, may be quoted without explicit permission provided that full credit, including $(\odot$ notice, is given to the source. 
Accounting for the Impact of Medicaid on Child Poverty

Sanders Korenman, Dahlia K. Remler, and Rosemary T. Hyson

NBER Working Paper No. 25973

June 2019

JEL No. H51,H53,I13,I14,I32

\begin{abstract}
$\underline{\text { ABSTRACT }}$
US Census Bureau poverty measures do not include an explicit need for health care or insurance nor do they consider health insurance benefits to be resources. Consequently, they cannot measure the direct impact of health insurance benefits on poverty. This paper reviews conceptual and practical considerations in incorporating health benefits and needs into poverty measures. We analyze the advantages and disadvantages of various approaches including variants of the Official Poverty Measure (OPM); the Supplemental Poverty Measure (SPM); using a threshold with medical out-of-pocket (MOOP) expenditures; a Medical Care Expenditure Risk (MCER) Index; willingness to pay (WTP) for Medicaid; and the Health-Inclusive Poverty Measure (HIPM; Korenman and Remler 2016). We present estimates of Medicaid's impacts on child poverty, based on the HIPM. This paper was prepared as a background paper for the Committee on Building an Agenda to Reduce the Number of Children in Poverty by Half in 10 Years, of the Board of Children, Youth and Families of the National Academy of Sciences. The paper was submitted in October 2017 and embargoed until the release of the Committee's report, A Roadmap to Reducing Child Poverty, in March of 2019.
\end{abstract}

Sanders Korenman

Marxe School of Public and

International Affairs

Baruch College

City University of New York

One Bernard Baruch Way

Box D-901

New York, NY 10010

and NBER

sanders.korenman@baruch.cuny.edu
Rosemary T. Hyson

Marxe School of Public and

International Affairs

Baruch College

City University of New York

One Bernard Baruch Way

Box D-901

New York, NY 10010

and CUNY Institute for Demographic Research

Rosemary.Hyson@baruch.cuny.edu

Dahlia K. Remler

Marxe School of Public and

International Affairs

Baruch College

City University of New York

One Bernard Baruch Way

Box D-901

New York, NY 10010

and NBER

Dahlia.Remler@baruch.cuny.edu

A data appendix is available at http://www.nber.org/data-appendix/w25973 


\section{Contents}

I. Why Consider the Role of Medicaid in Alleviating Child Poverty?

II. Overview of Difficulties of Incorporating Health Care and Insurance Benefits in Poverty Measures

III. Difficulties in Considering Medicaid’s Impact Using the Official Poverty Measure (OPM)

IV. Difficulties in Considering Medicaid's Impact Using OPM and Health Insurance Values in Resources

V. Difficulties in Considering Medicaid's Impact Using the Supplemental Poverty Measure (SPM)

VI. Difficulties in Considering Medicaid’s Impact Using Medical Out-of-Pocket (MOOP) Expenditures in the Threshold

VII. Difficulties in Considering Medicaid's Impact Using a Medical Care Expenditure Risk (MCER) Index

VIII. Estimates of Willingness to Pay (WTP) for Medicaid

IX. Health-Inclusive Poverty Measure (HIPM)

X. Results: Impact of Medicaid on Child Health-Inclusive Poverty

XI. Figure

XII. Tables

XIII. References 


\section{Why Consider the Role of Medicaid in Alleviating Child Poverty?}

Poverty is the state of having insufficient resources to achieve a minimally adequate standard of living. If a family unit is poor by this definition, all individuals in the unit are considered poor. Conceptually, considering Medicaid is important if health care is part of a minimally adequate standard of living and if Medicaid helps children and their families receive minimally adequate care. Medicaid is by far the largest benefit program (in terms of expenditures) for low-income families with children. It has also grown substantially since its inception in 1965, in eligibility, in real expenditures per beneficiary and in real per capita expenditures relative to other programs.

\section{Conceptual importance: consistent and complete poverty measurement}

Whether basic health care is part of the basic standard of living (i.e., a "basic need") is partly a matter of philosophy and social norms. Evidence that it is widely considered so includes that: nearly all higher-income countries have a form of national health insurance or care; an explicit goal of the Affordable Care Act was to achieve universal access to affordable health insurance; the 1948 Universal Declaration of Human Rights affirms health care as a basic right.

If health care is part of a minimally adequate living standard, Medicaid benefits directly alleviate child poverty by helping meet that need. The 1995 NAS/NRC report, Measuring Poverty: A New Approach (Citro and Michael 1995), recommended inclusion of in-kind benefits as resources, yet could find no valid way to include health insurance benefits. The report acknowledged that its treatment of health care was a fundamental weakness of its recommended approach. Most importantly, “...it does not explicitly acknowledge a basic necessity, namely medical care, that is just as important as food or housing. Similarly, the approach devalues the benefits of having health insurance, except indirectly” (p. 236). 


\section{Program size}

As of July 2017, 75 million people were enrolled in Medicaid (including CHIP), more than 1 in 5 Americans, nearly half of whom were children. ${ }^{1}$ Medicaid is means-tested, and therefore targeted on the low-income population. As a result, nearly half the noninstitutionalized population covered by Medicaid/CHIP had family income below the federal poverty line, and 81\% had income below twice the poverty line (MACPAC 2016 Exhibit 2, p. 6). Of the over $\$ 500$ billion spent on Medicaid (MACPAC 2016, Exhibit 16, p. 46), about $\$ 90$ billion each was spent on lowincome adults and children. ${ }^{2}$ As a result of means-testing and large expenditures per beneficiary, Medicaid has become the largest transfer program for the non-elderly low-income population. The $\$ 180$ billion spent annually on low income children and adults through Medicaid eclipses expenditures on any other means-tested benefit such as SNAP (Food Stamps) or refundable tax credits such as the EITC, at roughly $\$ 70$ billion each. $^{3}$

\section{Overview of Difficulties of Incorporating Health Care and Insurance Benefits in Poverty}

\section{Measures}

Ideally, a poverty measure should be able to show:

(1) whether or not children and their families have inadequate health care;

(2) whether or not children and their families have an inadequate material standard of living due to their obtaining adequate health care; and

\footnotetext{
${ }^{1}$ https://www.medicaid.gov/medicaid/program-information/medicaid-and-chip-enrollment-data/reporthighlights/index.html. Accessed October 1, 2017.

${ }^{2}$ See www.kff.org/medicaid/state-indicator/medicaid-spending-by-enrollmentgroup/?currentTimeframe=0\&sortModel=\{"colId":"Location","sort":"asc" $\}$. Accessed October 1, 2017. This last figure covers the period October 1, 2013 through September 30, 2014, and so does not reflect 12 full months of ACA Medicaid expansion spending, nor does it include spending on CHIP.

${ }^{3}$ https://www.fns.usda.gov/pd/supplemental-nutrition-assistance-program-snap and https://www.jct.gov/publications.html?func=startdown\&id=4971.
} 
(3) the extent to which Medicaid reduces the occurrence of those two conditions.

With these goals in mind, we assess different approaches to constructing a measure to estimate the impact of Medicaid on child poverty. The more general goal is to incorporate the need for health care in the poverty threshold and include health insurance benefits as resources to help meet that need. Poverty scholars long struggled to find a valid way to include an explicit need for health care in the poverty threshold and health insurance in resources but could not do so. Instead, they have used various indirect approaches or have relied on measures of non-health, material poverty (Moon 1993; Citro and Michael 1995). The difficulties they faced result from the distinct natures of health care needs and health insurance benefits. This section draws substantially from Moon (1993), Citro and Michael (1995) and Korenman and Remler (2013, 2016).

The distinct nature of health care needs

The fundamental challenge to putting health care in the poverty threshold is the nature of the need for health care. How much and what kind of health care people need depends on their health condition. One person may need no or little care, while another person, in otherwise identical economic circumstances, may need a great deal. Someone may need no health care in one year but a great deal the following year. The need for health care is both substantially unpredictable from one year to the next (stochastic) and substantially predictable from one year to the next (auto-correlated; see Hirth et al. 2016). The cross-sectional variation in health care needs is demonstrated by the skewness of total expenditures on care from any source: $5 \%$ of 
people consume about 50\% of health care expenditures (Mitchell 2016). ${ }^{4}$ Therefore, using any summary measure of total health care needs—-mean, median, $33^{\text {rd }}$ percentile or other-will result in substantial errors in both directions. Even summary measures conditioned on limited health status indicators will be substantially wrong much of the time (Meier 2016).

Health care needs, therefore, contrast dramatically with other needs, such as food needs. Essentially, everyone needs food in every period. Food needs do not vary nearly as much as health care needs either across individuals or across time for the same individual.

\section{The distinct nature of health insurance benefits}

Health insurance benefits also differ in nature from other in-kind benefits such as SNAP (Food Stamps). As an in-kind benefit, health-insurance benefits can be used only for health care, just as food assistance programs such as the SNAP can be used only for food purchases. However, since all people consume a substantial amount of food every month, a good share of SNAP replaces food expenditures that would occur in the absence of the benefit, and therefore it frees-up cash for other uses. But because most people need health care only occasionally, health insurance benefits are unlikely to free-up much cash that would have been spent on medical care in the absence of health insurance. Thus, health insurance benefits are not very fungible. Moreover, differences between food assistance benefits provided and food consumption will be small in comparison to the differences between thousands of dollars of Medicaid insurance benefits and the low medical care consumed by most beneficiaries in most periods. In other periods or for

\footnotetext{
${ }^{4}$ While the magnitude of the variability and skewness of health care needs is smaller for children than adults, it is still present. Moreover, children's economic well-being is affected by the well-being of adults in their household.
} 
other people, total expenditures on care will vastly exceed Medicaid benefits. That is the nature of health, health care and health insurance.

Difficulties of including a need for Medical Out-of-pocket Expenditures (MOOP) in the poverty threshold

An alternative to including a health care need in the poverty threshold is to include a need for out-of-pocket expenditures on medical care (MOOP) instead. However, this approach faces many of the same difficulties as putting health care in the threshold due to the irregular nature of the need for spending on health care linked to the irregular need for health care.

Moreover, making MOOP the basic need greatly limits the poverty measure’s ability to account for the direct impact of Medicaid or other insurance benefits on poverty. Medicaid provides the poor health care with essentially no out-of-pocket payments. If the MOOP need is conditioned on insurance type, then Medicaid recipients will have no MOOP need. In this case, Medicaid can have no direct impact on poverty by meeting their MOOP need (because that need is zero).

Another possibility would be to make the MOOP need the average out-of-pocket spending of the uninsured. This can show a meaningful MOOP reduction impact of Medicaid. But to the extent that the uninsured do not get needed care, this approach understates the need for care (or for MOOP that would pay for needed care), in turn understating the impact of Medicaid and other health insurance benefits on poverty. In essence, this approach would not show how insurance increases the consumption of needed care-the access value of care. (Nyman 2003, 2004; Sommers, Gawande and Baicker 2017). 
Finally, another possibility is to make the MOOP need the average MOOP expenditure in the population. To the extent that much of the population has health insurance benefits that lower MOOP, again, the full value of Medicaid in meeting care needs would not be measured. With this approach it would, however, be possible to measure how Medicaid impacts poverty by reducing MOOP from the average value to zero. As noted, all of the MOOP reduction impacts on poverty would also fail to capture the access-to-care value of Medicaid.

A possible solution: include a health insurance need in the poverty threshold Another approach is to consider the primary health care need to be a need for health insurance. A sufficiently good health insurance policy can ensure that all health care needs are met, however big or small. Moreover, that health insurance policy also meets the need for ex ante risk reduction—both financial (material) risk and health status risk (by providing access to care).

Designating health insurance as the fundamental health care need eliminates the problems of including care in the threshold, provided health insurance prices do not vary substantially with health conditions. Health insurance resources and health insurance needs must still be calculated in a consistent manner. Because health insurance cannot be used to purchase food or other material needs, health insurance benefits should never be valued above health insurance needs. If these conditions are met, it becomes possible to estimate the impact of Medicaid and other health insurance benefits on poverty, as we will describe later. 
To sum up, it is difficult to determine a need for health care for the purpose of poverty measurement, because care needed varies greatly among individuals and over time for a given individual. The same is true for the need for medical out-of-pocket spending (MOOP). Additionally, if the health care need is a need for medical out-of-pocket spending only, then the estimated direct impact of Medicaid on poverty will understate the MOOP reduction value of Medicaid and miss entirely its access-to-care value. Lastly, because of their distinct nonfungibility, health insurance benefits can only be counted in resources if there is a consistent health care/insurance need in the threshold.

We will refer to the issues summarized in this overview in describing problems with considering Medicaid's role in child poverty using different poverty measures

\section{Difficulties in Considering Medicaid's Impact Using the Official Measure (OPM)}

The OPM resource measure includes only cash income and excludes all in-kind benefits. Thus, without modification, the OPM as such cannot be used to account for the direct impact of health insurance benefits such as Medicaid on poverty through meeting of health care needs.

The OPM needs threshold is defined as three times the cost of USDA Thrifty Food Plan in the early 1960s, adjusted annually for overall price inflation. Thus, it does not include an explicit budgetary component (“need") for either health care or for out-of-pocket expenditures for care or insurance. However, through the "three times" multiplier, the OPM threshold does include an implicit need for out-of-pocket health care and insurance expenses. This budget share for out-of- 
pocket expenses has been estimated to be in the range of $4 \%$ to $7 \%$ of the poverty threshold. ${ }^{5}$ Thus, the health care need implicit in the OPM threshold is for out-of-pocket spending only; it does not include a need for medical expenses that could be covered by insurance (NAS p. 226).

Because the OPM threshold includes only out-of-pocket expenditures, it cannot be used to validly measure the full impact of Medicaid or other health insurance benefits in meeting a need for out-of-pocket payments and for accessing care, as discussed in Section II.

Even as a measure of the need for out-of-pocket medical spending, the OPM threshold has several weaknesses. The OPM threshold assigns all families of the same size and age composition the same need for out-of-pocket spending. An uninsured family has the same need for medical out-of-pocket expenses as an otherwise identical insured family. That need is also not adjusted for differences across even crude categories of risk for out-of-pocket expenditures such as age or insurance type. Moreover, within risk categories, health care needs and out of pocket expenditures depend on health status, and are skewed.

Another potential problem often noted (e.g., Citro and Michael 1995 p. 231) is that the $4 \%$ to $7 \%$ implicit budget share for medical expenses from the 1960s may be out of date. On the one hand, the cost of health care has grown tremendously. On the other hand, a higher portion of medical expenditures is paid by third-party payers, especially following the establishment of Medicare and Medicaid in 1965. As a result, the average budget share of medical expenditures is still

\footnotetext{
${ }^{5}$ According to the NAS report (Citro \& Michael, 1995, p. 226): "Median [out-of-pocket] expenses accounted for 4 percent of median income in 1963 (Moon, 1993: 3); 7 percent of total expenditures in the 1960-1961 CEX (Jacobs and Shipp, 1990: Table 1); and 5 percent of personal consumption expenditures in the 1960-61 NIPA (CEA, 1992: Table B-12)”; See also Burtless and Seigel (2004, page 123).
} 
around 8\%. ${ }^{6}$ Nonetheless, because real family income has grown since the early 1960 s, real average medical out-of-pocket expenditures are much higher today. Since the OPM poverty thresholds are fixed in real terms, the $\$ 4,500$ spent by the average family on medical out of pocket expenses today is large relative to the OPM poverty line: $23 \%$ for a family consisting of one adult and two children and 18\% for a family with two adults and two children.

\section{Difficulties in Considering Medicaid's Impact Using OPM and Health Insurance Values in Resources}

The size and rapid growth of flows to low-income households of in-kind benefits, particularly food, housing and medical assistance, motivated attempts to include them in the OPM resource measure (Smeeding 1977, p. 366). Various modifications of the OPM resource measure have been used to assess the impact of in-kind benefits on poverty counts, rates or gaps. We review the various approaches to adding a value for Medicaid and other health insurance benefits to OPM Resources.

A key limitation of all these approaches is that, despite modifications, the resource measures continue to be inconsistent with the health care need in the OPM threshold. Moreover, the health care need in the OPM threshold is an implicit amount for out-of-pocket expenses through the “three times” multiplier and does not include a need for care that could be paid by insurance.

\footnotetext{
${ }^{6}$ In 2014, household spending on health care and insurance as a percent of total expenditures reached $8 \%$ and the average expenditure was nearly $\$ 4,500$ (Foster, 2016).
} 
Therefore, no approach that adds a value for Medicaid to the OPM resource measure is consistent with the need for out-of-pocket spending implicitly incorporated in the OPM threshold. In recognition of the importance of these issues, the first recommendation included in the 1995 NAS report's chapter on resources (Citro and Michael, p. 206, emphasis in original) was:

\section{"Recommendation 4.1 In developing poverty statistics, any significant change in the definition of family resources should be accompanied by a consistent adjustment of the poverty thresholds."}

The report continued “...to add the value of health insurance benefits to income (in whole or in part) but not to add any amount to the poverty thresholds—-to allow either for medical care needs that would be covered by insurance or for higher out-of-pocket medical expenses—is to ignore completely the increased costs of medical care and to assume the fungibility of medical care benefits. This approach is perverse, particularly for people with high health care needs (who may also have above-average out-of-pocket costs). As we recommend above (Recommendation 4.1), poverty estimates of this type are not appropriate.”

Needs and resources must be consistent. Moreover, as explained in Section II, if needs are only for MOOP, then the poverty measure cannot show the full value of Medicaid. It will understate the direct impact that Medicaid has in reducing MOOP, and miss entirely the value of Medicaid in ensuring access to needed care. 
Approaches to valuing health insurance for OPM resources

In a technical report for the US Census Bureau, Smeeding (1982) compared different approaches

to valuing in-kind benefits including a market value, recipient (cash equivalent) value and

poverty budget value. ${ }^{7}$ Subsequently, the Census Bureau has made available a "fungible value"

of health insurance, to approximate the recipient (cash equivalent) value. Each of these is

discussed in turn.

The market value is simply the amount paid for the equivalent good in the market (e.g., the price of a health insurance policy or the actuarial value of health insurance benefit including government benefits). ${ }^{8}$ Studies that have presented results using this approach to valuing Medicaid include (CBO 2012 p. 18-21 Ben-Shalom, Moffitt, and Scholz 2012; Burkhauser, Larrimore and Simon 2012, 2013).

The distinct nature of the health care needs and the resulting much lower fungibility of health insurance than other in-kind benefits, described in Section II, raised questions about this approach. The major objection to including the full market value in resources was the implication that the poor could use Medicaid to meet non-health needs, such as food. Furthermore, the magnitude of the resulting poverty impact implied that many poor families could nearly escape poverty on the basis of health insurance alone. For example adding a market

\footnotetext{
${ }^{7}$ Smeeding (1982) also estimated a poverty budget share approach that caps the value of an in-kind benefit at the share spent on the item by families near the poverty threshold in 1960-61, prior to the expansion of major federal food and Medical insurance programs. Since out-of-pocket expenditures were a small percent of spending at the poverty line in the early 1960s, this method results in very small values of health insurance programs. To our knowledge, this approach has not been widely used, and will not be discussed here further. See also Smeeding (1977).

${ }^{8}$ We use the terms "market value" and "actuarial value" interchangeably. The actuarial value is the expected or average medical cost of care paid by the insurer for a defined pool of insured. For private insurance, the market value is the actuarial value plus "loading" (administrative costs and profits).
} 
value of Medicaid and Medicare to the OPM resource measure reduced the 1986 poverty rate for children from 20.5 to 16.1 percent and for persons over age 65 from 12.4 to 4.1 percent (Citro and Michael, Table 4-2). Smeeding (1982, Table 14) showed that the market value of Medicare and Medicaid alone (excluding institutional care) amounted to 40 percent and 64 percent of the poverty threshold for one- and two-person households, respectively, in 1979.

Analysts who use market values sometimes have expressed ambivalence. For example, BenShalom, Moffitt and Scholz (2012) wrote: “...OASI, Medicaid, and Medicare have the largest impact at all poverty levels...The fact that two of these programs are less valuable than cash must temper this conclusion.” The large values of health insurance benefits compared to the small budget share for out-of-pocket medical expenditures of low-income households in the needs threshold suggested to many that the market value approach is invalid on its face.

The recipient cash-equivalent value is the "amount of cash income needed to induce families to forgo a particular in-kind benefit” (Smeeding, 1977, p. 364); this is sometimes referred to as the recipient "willingness to pay” for the benefit. Attempts have been made to estimate willingness to pay by modeling utility-based family economic welfare, though as Smeeding (1982) noted: "Even though recipient cash equivalent value is the theoretically preferred measure, it is quite difficult to estimate, especially for medical care.” ${ }^{10}$

\footnotetext{
${ }^{9}$ This may be the theoretically correct measure for use in aggregating cash and in-kind benefits for income distribution measures, but whether or not it is the theoretically preferred method for use in poverty measurement depends on whether and how the need for health care is incorporated in the poverty threshold.

${ }^{10}$ See Finkelstein, Hendren and Luttmer (2016) for a recent example of valuing Medicaid using this approach, and a discussion of modeling issues.
} 
Rather than specifying a family utility function, Smeeding $(1977,1982)$ estimated the cash equivalent value of Medicaid to a recipient family by observing the spending of observationally equivalent reference families that have cash income equal to the recipient family's cash plus market value of insurance. The recipient value of insurance is equal to the smaller of the market value of insurance and the expenditure of the reference family on medical care and insurance. For example, suppose a recipient family has $\$ 10,000$ cash income and a Medicaid policy with a market value of $\$ 4,000$. The method calculates the average expenditures on health care and insurance of families with cash income of $\$ 14,000$ and no Medicaid or other insurance. If, on average, the reference families spent $\$ 2,000$ on medical care and insurance, then the cash equivalent value of the policy to the recipient family is $\$ 2,000$. If the average reference family spends more than $\$ 4,000$, the cash equivalent value of Medicaid is the market value, $\$ 4,000 .{ }^{11}$

For 30 years the Census Bureau has calculated a "fungible value" for Medicare and Medicaid for alternative poverty estimation (e.g., Census 1988a, 1988b). The fungible value approach assumes that health insurance has value only to the extent it frees up cash that would have been spent on other necessities. Essentially, it assumes that no expenditures on health care and insurance would be made unless food and shelter needs are met. After those needs are met, potentially all remaining cash income could be spent on health insurance or care. As a result, for families with cash income plus food and housing assistance income less than a food and shelter need standard, the fungible value of Medicaid is zero. For families with cash and food and shelter assistance income in excess of the food and shelter standard, the fungible value of

\footnotetext{
${ }^{11}$ This calculation ignores the fact that the uninsured reference family might have been willing to spend $\$ 4,000$ on an equivalent insurance policy but, because of pre-existing conditions, they were unable to buy a policy at that price; in this situation, they may also spend less by foregoing needed care.
} 
Medicaid is the difference between the market value of Medicaid and the food and shelter need standard, up to the full market value of Medicaid (Census, 1993, page viii). Census' fungible value approach has been used by many analysts including Meyer and Sullivan (2012); CBO (2011); and Hoynes, Page and Stevens (2006).

Not surprisingly, using a fungible or recipient value for health insurance yields poverty rates that fall between those based on either a zero value or the full market value of health insurance transfers to low-income families. For example, Census (1988a) estimated that, in 1987, among children under 6 , the official poverty rate would fall by 5.1 or 1.3 percentage points using market or recipient value, respectively. ${ }^{12}$ For children aged 6 to 17 , these impacts were 4.7 and 1.3 percentage points. Similarly, when a fungible or recipient value was used, Medicaid and Medicare reduced child poverty modestly in 1986 , from $20.5 \%$ to $19.2 \%$ or $19.0 \%$, respectively (Citro and Michael, Table 4-2). For those over 65, the poverty rate was lowered from 12.4\% to 9.1\% or $8.2 \%$ using, respectively, a fungible or recipient value for Medicare and Medicaid.

Meyer and Sullivan (2012; 2013) showed that adding a fungible value of health insurance to consumption has only a trivial effect on the trend in consumption poverty rates between 1980 and 2010. ${ }^{13}$ (The consumption poverty rate is the fraction of the population consuming below the poverty threshold.) The small impact on the consumption poverty trend is surprising given the enormous increase in real expenditures on Medicaid, Medicare and CHIP, the expansion of eligibility for these programs, and, more generally, the increased cost of health care over this

12 The impacts of health insurance were calculated after non-health in-kind benefits were added to resources.

${ }^{13}$ See Meyer \& Sullivan (2012) and on-line appendix, Meyer \& Sullivan (2013). The consumption deep poverty rate was $1.8 \%$ in 1980 and under 1 percent in 2010, whether or not resources include health insurance benefits. 
period. For example, inflation-adjusted spending on Medicaid in 2006 was nearly five times what it was in 1980, and the number of recipients more than doubled (Scholz et al., 2009 Table 8A.1 and 8A.2).

In contrast, including health insurance in resources has a large impact on the trend in consumption near-poverty (consumption $<150 \%$ of the federal poverty level); instead of falling 7 percentage points (from $34.8 \%$ in 1980 to $28.0 \%$ in 2010), the near-poverty rate falls 19 percentage points (Meyer and Sullivan 2013, Appendix Table 13). The larger impact of health insurance on trends in consumption near-poverty than consumption poverty is likely the result of the use of the fungible values for Medicare and Medicaid, which assigns much lower values of insurance at lower levels of income. ${ }^{14}$

While more modest poverty impact estimates such as these might suggest that a fungible or cashequivalent value has more face validity for poverty measurement than a market value, the fungible value method also has weaknesses.

First, it underestimates the value of insurance in many cases. Smeeding’s (1977) cash equivalent method places a zero value on Medicaid above the expenditure share of the reference family. Martin Feldstein, in discussing Meyer and Sullivan’s presentation at the Brooking Institution noted that "very poor households have little cash to free up, so the [fungible value] calculation results in Medicaid appearing to have little value for them” (Meyer and Sullivan, p. 196).

\footnotetext{
${ }^{14}$ Winship (2016) estimated the impact on child poverty of adding $25 \%$ of the market value of employer insurance, Medicaid and Medicare to OPM family resources as a conservative estimate of the cash-equivalent value of health insurance. Compared to not valuing health insurance benefits at all, valuing them at $25 \%$ of market value lowered the child poverty rate from $20.5 \%$ to $18.9 \%$ in 1996 and from $19.5 \%$ to $17.0 \%$ in 2014 .
} 
Kaestner and Lubotsky (2016, p. 62) argued that, even among families with income below the food and shelter need standard for whom the fungible value of health insurance is zero, health insurance raises consumption of health services and must, therefore, have value.

The difference between actuarial and fungible valuation of health insurance provided through Medicare, Medicaid, and CHIP is enormous, about \$200 billion in 2009 (CBO, 2012 p. 18-20); using a market rather than fungible value “...increased CBO’s estimate of average income for households in the bottom quintile of the before-tax income distribution by roughly $\$ 4,600$ (or nearly 25 percent) and for households in the second quintile by roughly $\$ 1,600 . ”$

Second, even if the fungible value is regarded as a reasonable compromise between excluding health insurance from resources and including their full market value, it (again) is conceptually inconsistent with the OPM's implicit health need, which is a need for out-of-pocket expenses. Thus, Moon (1993, p. 6) observed that “...even creative ways of adjusting downward the value of health benefits received merely masks the [inconsistency] problem rather than resolving it.”

\section{Difficulties in Considering Medicaid's Impact using the Supplemental Poverty Measure}

The Supplemental Poverty Measure (SPM), first published by the Census Bureau in 2011, implemented many of the recommendations of the NAS Report (Fox 2017; Citro and Michael 1995). The SPM thresholds are intended to define non-health needs: food, clothing, shelter and utilities (FCSU) and “a little more.” The SPM resource measure includes values for in-kind 
benefits that meet these needs, but not Medicaid, Medicare or other health insurance benefits. The SPM is explicitly a non-health, "material” poverty measure.

Rather than include health care or insurance needs in the SPM threshold, the SPM accounts for the need for only out-of-pocket medical expenses, and does so implicitly, by subtracting out-ofpocket expenditures on insurance, medical care and over-the-counter medicines from resources. This deduction is justified by the assumption that all health care expenditures are "nondiscretionary," like taxes, which are also deducted from resources. Thus, this approach implicitly assumes that whatever a family spends out-of-pocket on health care, OTC or insurance is their health need: no more and no less. It also assumes that the income spent on MOOP could not be used to meet the family's other basic needs.

Under this assumption, SPM made the resource and threshold conceptually consistent, but did so by excluding health care paid for by third parties from both. In recognition of this exclusion, the NAS report recommended the development of a separate medical care economic risk index (MCER) that could be used in conjunction with the SPM to provide a more complete description of needs and resources. We discuss MCER in Section VII.

The SPM treatment of health insurance and care has some disadvantages. As noted, the SPM excludes health insurance from resources and health insurance needs from the poverty threshold. With no health insurance need in the SPM threshold, it would be inconsistent to add a value of Medicaid or other insurance benefits to SPM resources. As a result, the SPM cannot be used to estimate the direct impact of health insurance benefits on poverty. 
The SPM can be used to estimate the indirect, partial impacts of health benefits on material poverty, through their effects on the MOOP deduction. Sommers and Oellerich (2013) estimated an impact of Medicaid on SPM child poverty of 1.0 percentage point. Yet, as they note (p.829), these estimates are indirect impacts of Medicaid on SPM poverty through MOOP reductions and do not capture Medicaid's “presumed primary benefit of improved access to care and health.”

Since the SPM does not include a need for health care, it also cannot detect unmet health care or health insurance needs. If a low-income uninsured person cannot access needed care, the SPM does not register his unmet need nor classify him as poor as a result.

As Cogan's (1995) dissent from the 1995 NAS report suggests, the SPM will assign different poverty statuses to families in identical health and financial circumstances who make different health care or insurance choices. For example, it will classify as poorer (through the MOOP deduction) people who, all else the same, choose to get more or better health care or insurance. Korenman and Remler (2016) noted that this feature of the SPM could also distort the impact of the Affordable Care Act on poverty. Premium payments for even highly subsidized insurance can make families appear poorer because the SPM deducts premium payments from resources but does not add a value to resources for the highly subsidized insurance they receive in return.

\section{Difficulties in Considering Medicaid's Impact with Medical-Out-of-Pocket Expenditures (MOOP) in the Threshold}


Although the SPM accounts for medical-out-of-pocket expenditures (MOOP) needs by subtracting actual MOOP expenditures from the resource measure, an alternative approach that has received some attention adds an expected need for MOOP to the SPM poverty threshold. This approach is sometimes referred to as "MOOP in the threshold.” Examples include Burtless and Siegel (2004) and Garner and Short (2010). For brevity, we summarize Garner and Short.

Garner and Short (2010) implemented an SPM-like poverty measure (based on NAS 1995 recommendations) that included a MOOP need in the threshold. They refer to the resulting thresholds as "FCSUM" indicating that a need for medical expenditures ("M") has been added to the SPM-like threshold that measures the need for food, clothing, shelter and utilities (FCSU). Ben-Shalom, Moffitt and Scholz (2012; Table 4) used Garner and Short’s thresholds for some of their analyses; their poverty rate, trend, gap and transfer impact estimates were not very sensitive to the choice of threshold (FCSUM rather than FCSU).

Garner and Short's approach determines the FCSUM expenditures at the $30^{\text {th }}$ to $35^{\text {th }}$ percentile of the distribution of expenditures among reference families consisting of "two related adults and children” (p. 9-11). The method adjusts the FCSU portion of this expenditure upward to account for additional needs, including non-work transportation, personal care, education and reading materials. Similar to the SPM, an equivalence scale is applied to the FCSU portion of the reference family's expenditure to produce a set of FCSU thresholds for families of different sizes and age compositions. 
The MOOP portion of FCSUM for other family types is determined by a set of "medical risk indexes” linked to family size, age of members and information on health insurance coverage. These indexes produce ratios of MOOP needed, relative to the MOOP need of the reference family. These are applied to the FCSU thresholds to produce the full set of FCSUM thresholds. ${ }^{15}$

For the reference family (two adults, two children) in 2005, the FCSU and FCSUM thresholds are, respectively $\$ 22,769$ and $\$ 24,784$; the ratio of FCSU/FCSM is $91.9 \%$ (Garner and Short, 2010, Table 1) and the two thresholds increased similarly between 1996 and 2005 (Chart 1). ${ }^{16}$ This ratio is much smaller than the ratio of the SPM threshold to our Health Inclusive Poverty Measure threshold for the same family: 71.2\% in 2014 (see Table 1 below). The difference in these ratios reflects differences in the medical portion of the two thresholds. The "M" portion of FCSUM is out-of-pocket expenses on both care and premiums. In contrast, the health need in the HIPM threshold is the full cost of health insurance, valued at the unsubsidized premium of a plan on the ACA Marketplace.

If only a MOOP need is added to the threshold, then a value for health insurance should not be added to the resource measure, and so the direct impact of Medicaid and other health insurance benefits cannot be estimated. Discussions of the MOOP-in-the-threshold approach (e.g., National Research Council 2005, p.17-20) have noted that a need for health insurance for the uninsured could, in principle, be included in the MOOP need. ${ }^{17}$ However, in the absence of guaranteed

\footnotetext{
${ }^{15}$ MOOP appears to include both premium and non-premium MOOP. While Garner and Short (2010) does not state this explicitly, it is true for the usual SPM MOOP subtraction and standard in BLS reports (e.g. Foster 2016) based on the Consumer Expenditure Survey data that Garner and Short (2010) used.

${ }^{16}$ The similarity between FSCU and FCSUM threshold likely explains the insensitivity of Ben-Shalom et al.'s (2012) results to this choice.

${ }^{17}$ See Burtless and Siegel (2004) for an example.
} 
issue and community rating regulations such as those required by the ACA, the actual cost of health insurance to the uninsured could not be determined without very detailed information on the family's health status, and perhaps not even then (Korenman and Remler 2016).

\section{Difficulties in Considering Medicaid's Impact Using a Medical Care Expenditure Risk (MCER) Index}

The NAS Report (Citro and Michael 1995) acknowledged that the recommended poverty measure could not show unmet health care needs or the value of health insurance benefits in meeting them. The panel recommended a measure of medical care economic risk (MCER) be developed to supplement their recommended material poverty measure. An expert panel sponsored by the US Department of Health, the National Research Council and the Institute of Medicine issued a report (O’Grady and Wunderlich 2013) with recommendations on developing an MCER. The report defined an MCER as "for example, the expected number (or fraction) of families or their individual members who, as a result of out-of-pocket spending for medical care services and premiums, would be in poverty or some multiple of poverty as defined by the SPM" (p. 7). A chapter in the report by Meier and Wolfe, as well as comments by workshop participants, laid out key components of and challenges in implementing an MCER, many of which are described here.

Meier (2016) extended this work, by taking the first step of modelling individual health risk as a function of individual health characteristics. Meier emphasized the importance for an MCER of 
the richness of the health data: "A model developed using risk score cells would require access to claims data or the use of an extensive health questionnaire to assign individuals to a risk level based on a risk score.” An alternative approach is to develop a model based on self-reported health status, which is available in the Current Population Survey (CPS).

Meier used the Medical Expenditure Panel Study (MEPS) 2002-2009 to compare these two approaches. Specifically, she compared risk classification strategies that used:

1. Self-reported health status as the only health condition or status information;

2. DxCG risk score, a measure of expected (ex ante) total medical expenditures developed for risk adjustment, calculated from the extensive diagnosis and health information in the MEPS. ${ }^{18}$ MEPS respondents were allocated to five different risk classification groups with the cut-offs for DxCG scores chosen to match population shares in self-reported health status. Risk scores were also conditioned on insurance status: Medicare, Medicaid or private (presumably direct purchase and employer-sponsored combined). Meier (p.289) found that the two strategies produced "substantial differences in cell-level classification and attributed expenditure risk.”

Abramowitz, O'Hara and Morris (2017) used the CPS to implement an MCER. They estimated non-premium MOOP expenditures for a family using a Poisson model with random intercepts at the family-level. Their predictors were: the demographics and self-reported health status of all individual family members, as well as family structure and income. They did not include health insurance status in their model, because it is endogenously determined. Risk for a cell (a group defined by certain characteristics) is modelled as the distribution of family random intercepts in

\footnotetext{
${ }^{18}$ DxCG is a commercially available algorithm and software widely used for risk adjustment (Society of Actuaries 2016), usually applied to claims data.
} 
that cell. They estimated separate models for families with members under 65 and for families with members over 65. Abramowitz, O’Hara and Morris’ measures of risk are estimated by health insurance type (9 categories for the under-65 and 3 categories for the $65+$ ).

Abramowitz, O’Hara and Morris defined resources available to pay for non-premium MOOP or for health insurance (premium MOOP) as income after taxes and tax credits, and they used the official poverty measure definition of material needs. Using the distribution of MOOP expenditures for each cell, calculated as the sum of predicted expenditures and the distribution of random intercepts, they estimated the probability that a family will not have the resources to meet MOOP expenditures, conditional on its place within the distribution.

Their bottom line estimates are (p. 469): “ $21.3 \%$ of families lack the resources to pay for the median expenditures for their insurance type, $42.4 \%$ lack the resources to pay for the $99^{\text {th }}$ percentile of expenditures for their insurance type” in 2013. They also estimate how distributions of expenditures vary by insurance status.

Irrespective of its role in incorporating health care and health insurance benefits into poverty measurement, the MCER is valuable in estimating the likelihood that families will face difficulty affording health care expenditures and how different health policies affect that likelihood. From the perspective of a poverty measure, the MCER clearly could add value to the SPM, but also presents difficulties. 
The MCER can produce a statistic analogous to a poverty rate-the population share with unmet needs - provided a threshold (acceptable) level of risk is specified. For example, if a 10\% probability of not being able to meet medical care expenditures is chosen, the MCER poverty rate could be defined as the share of families who lack resources to pay for the $90^{\text {th }}$ percentile of expenditures.

An MCER poverty rate, however, contrasts with the usual ex post notion of poverty, because, on average, $10 \%$ of the families deemed not poor by this approach will in fact will lack sufficient resources to pay for medical expenditures. On the other hand, by incorporating a need for care $e x$ ante (i.e., everyone's ex ante risk), the MCER approach improves upon the entirely ex post perspective of the SPM.

The MCER is based on empirical health care expenditures. Therefore, it cannot show the extent to which health care needs go unmet or result from paying for excessive care, care above what society might define as meeting basic needs.

The MCER has the potential to estimate the value of health insurance benefits in enabling payment for health care after meeting material needs. However, to date and to our knowledge, no one has estimated an impact of health insurance benefits, such as Medicaid, on an MCER poverty rate.

As Meier (2016) demonstrated, current data limitations mean that MCER estimates suffer from one of two shortcomings: 
(1) If the CPS is used: low accuracy of medical care expenditure risk due to limited health information (self-reported health status), but good income data.

(2) If the MEPS is used: Few measures of income (material resources) and needs but more health status data and therefore more accurate medical care expenditure risk estimates.

As medical technology and government and market health plan features change, the distribution of medical expenditures and its relationship to estimating covariates will change. Therefore, it will not be possible to simply estimate risk scores by covariates and use them for significant periods. Thus, the considerable data and econometric requirements for the MCER risk scores estimates are a substantial weakness of the approach.

\section{Estimates of Willingness to Pay (WTP) for Medicaid}

A related yet distinct literature seeks to understand how measures of income inequality and changes in inequality over time would be affected by valuing health insurance benefits as income. This literature does not present poverty rates or impacts on poverty. Nonetheless, it also seeks to value health insurance for the measurement of income and therefore provides insights for poverty measurement.

A series of recent articles estimate the willingness to pay for health insurance (Finkelstein, Hendren and Shepard, 2017; Finkelstein, Mahoney and Notowidigdo, 2017; Finkelstein, Hendren and Luttmer, 2016). Finkelstein, Hendren and Luttmer (2016) use information from the Oregon Health Insurance Experiment to value willingness to pay for Medicaid among low- 
income adults This is one of only a handful of studies that use exogenous variation in prices of insurance to directly study willingness to pay (see Finkelstein, Hendren and Shepard 2017 page 3 for a summary of evidence of this type). Finkelstein, Hendren and Luttmer (2016) find that willingness to pay for Medicaid is far below its actuarial value, with a ratio of willingness to pay to market value typically between 0.2 and 0.5 .

Does this mean that OPM-like poverty measures should value Medicaid benefits in resources at only $20 \%$ to $50 \%$ of actuarial value? We believe that would be a misapplication of this study result. First, as noted, adding this recipient value to family resources only makes sense if there is a "need" for health care in the poverty threshold that is consistent with resources. It is far from obvious what the appropriate need would be, and whatever that is, it is not currently a part of either the OPM or the SPM threshold.

Second, Finkelstein, Mahoney and Notowidigdo (2017, p. 16) and Finkelstein, Hendren and Luttmer (2016, p. 6 \& 32) review evidence and conclude that the low willingness to pay for Medicaid among low-income uninsured families reflects the widespread availability of free care- a different resource used to meet health care needs. This finding has important implications for how the WTP should and should not be used in poverty measurement. More specifically, these papers conclude that extensive free care amounts to substantial implicit (partial) insurance. This implicit partial insurance takes the form of uncompensated care from hospitals, free clinics, and uncollected medical debt (e.g., Garthwaite et al. 2015). In the Oregon Health Insurance Experiment, the uninsured (the "control compliers”) got nearly as much care as those insured by Medicaid as a result of the experiment (the "treatment compliers"), although the 
controls also spent somewhat more out of pocket. As a result, the implicit insurance payments to the uninsured control group were about $60 \%$ of those to the experimental Medicaid group. ${ }^{19}$

It might be appropriate to value Medicaid at the WTP value among the uninsured (estimated as 20 to $50 \%$ of actuarial value) if the intention is to estimate Medicaid's net value above and beyond implicit insurance provide by free care. However, Medicaid (and subsidized insurance to low-income persons) is explicitly intended to replace this partial implicit insurance. For example, in recognition of this goal, the ACA is partly funded by reduction of federal reimbursement to hospitals for uncompensated care to the uninsured (e.g. Anotonise, Garfield, Rudowitz and Artiga 2017). Put differently, if we want to account for all the resources of the poor, we would want to add an actuarial value for implicit insurance to the resources of the uninsured, and, for Medicaid recipients, either the full actuarial value of Medicaid or the sum of the implicit insurance value of their free care and their WTP for Medicaid above and beyond implicit insurance.

Indeed, Finkelstein, Hendren and Luttmer (2016, p. 33) also provide utility-based estimates of the "value to recipients if the uninsured had no implicit insurance.” These estimates, although speculative (because based on extrapolation out-of-sample), may nonetheless be more relevant for assessing the value of Medicaid benefits for the incomes of the poor. These estimates range from \$2,233 to \$3,875 (in 2009 dollars), and are substantially larger than their estimated WTP for Medicaid among the uninsured who have access to implicit insurance. Thus, their estimates

\footnotetext{
${ }^{19}$ The ratio of the economic welfare of the two groups was higher than $60 \%$ due to the assumption of diminishing marginal utility of consumption.
} 
of the value if the uninsured had no implicit insurance range from $62 \%$ to $107 \%$ of actuarial value-the midpoint of this range is $85 \%$. These estimates come from a sample of poor adults who gained (or were denied) eligibility for Medicaid through experimental random assignment. In Section X, we incorporate their estimate of the implicit insurance payments for the uninsured into one of our alternative estimates of the impact of Medicaid on child poverty.

\section{Health-Inclusive Poverty Measure (HIPM)}

\section{Conceptual basis}

Sections II-VIII have described the difficulties poverty analysts faced in incorporating a need for health care in poverty measures and estimating the impact of Medicaid and other health insurance benefits on poverty. The key underlying barrier was an inability to include a comprehensive, valid health need in the poverty threshold. Health care is broadly considered part of an adequate living standard. However, determining a health care need, in dollars, to add to the poverty threshold was not possible, because health care needs vary so much, depending on detailed health condition. A practical solution to this problem is to make health insurance the primary health need.

Needs are always socially, politically and philosophically determined. The political conflict about government provision of health insurance demonstrates a lack of clear consensus. Nonetheless, we appeal to the political authority of the Affordable Care Act (ACA) to justify treating health insurance as the basic health need. 
Including a health insurance need in the poverty threshold was not possible in the US prior to the full implementation of the ACA in 2014. Determining the dollar amount needed to purchase health insurance often required the kind of medical detail that emerges from medical underwriting. Knowing which people were subject to such underwriting required details about employment, employment insurance offers and other circumstances. In 2014, however, guaranteed issue and community rating regulations of the ACA went into effect. These regulations allow anyone to purchase health insurance and at a price that does not depend on health status, making it possible to put a dollar value on health insurance needs.

The HIPM approach is best understood through the idea of a Basic Plan:

"[C]onsider a health care system that makes eligibility universal for basic insurance, the "Basic Plan.” The Basic Plan covers all care deemed essential by society; so it is complete in the events, treatments and procedures covered. However, it does not fully pay for all essential care. First, people must pay part of the premium out-of-pocket (premium MOOP). But that premium is not risk-rated: it does not depend on health status. Second, the Basic Plan includes cost-sharing, such as deductibles and co-pays (nonpremium MOOP), although it caps cost-sharing payments. In such a system, all essential health needs can be met with premium MOOP equal to the Basic Plan premium and nonpremium MOOP less than or equal to the Basic Plan nonpremium MOOP cap. Any premium MOOP payments above the Basic Plan premium and any nonpremium MOOP payments above the Basic Plan cap are discretionary, as socially defined.” (Korenman and Remler 2016, Section II) 
The ACA created essentially these conditions. Exchange plans have premiums that do not depend on health status and that cap non-premium MOOP expenditures. Almost everyone can purchase Exchange plans. Undocumented individuals cannot purchase plans on the exchanges, but because they can purchase off the exchanges from insurers subject to guaranteed issue and community rating regulations, their health insurance need is defined. People eligible for Medicare and Medicaid also cannot purchase on the exchanges but have plans that essentially meet the criteria.

Still, poverty measurement requires the designation of an ACA Exchange plan as the Basic Plan. The ACA provides a natural choice for such a plan, the second cheapest Silver plan available in a household's rating area, because the ACA premium subsidies are calculated to ensure that plan is affordable. Moreover, ACA cost-sharing reduction subsidies are only available for Silver plans. Thus, we designate the second cheapest Silver plan, with substantial cost-sharing for some, as the specific insurance need for most families with children. For consistency, this Silver plan is the Basic Plan for everyone other than Medicare beneficiaries. For Medicare beneficiaries, we designate the cheapest available Medicare Advantage Prescription Drug Plan as the Basic Plan. ${ }^{20}$

If the universally available Basic Plan fully covered all health care that society deems essential, putting the health insurance plan premium in the threshold would be sufficient. To the extent, however, that the insured must pay for cost-sharing, such as deductibles, cost-sharing needs must also be addressed. Incorporating cost-sharing needs has the problems described in earlier sections for incorporating health care needs: they vary substantially among people and across

\footnotetext{
${ }^{20}$ For those over age 65 who are not Medicare recipients, we designate the second-cheapest Silver plan for 64 year olds as the basic plan since those aged 65 and over are eligible to purchase such plans (e.g., Norris, 2019).
} 
time. The magnitude of these problems is, however, smaller than for the full cost of health care. Moreover, the ACA includes provisions that cap total cost-sharing payments (non-premium MOOP) and consequently bound the magnitude of those problems. The lower the caps, the smaller the magnitude of the problem of incorporating cost-sharing needs. Medicaid has little or no cost-sharing, so these problems are very small or not present for Medicaid recipients.

With this approach we can create a health inclusive poverty measure (HIPM) which has an explicit need for health care in the threshold (through the explicit need for health insurance) and that counts health insurance benefits as resources to meet that need.

\section{HIPM implementation summary}

While a HIPM with this conceptual basis could be built on different poverty measures, our HIPM is a modification of the SPM. The SPM has two essential features for this purpose: in-kind benefits other than health insurance are counted in resources and all the needs included in the threshold are made explicit (food, clothing, shelter and utilities and bit more for other non-health needs). Figure 1 (page 26) outlines the components of the OPM, SPM and our HIPM. Except where noted, our HIPM methods are the same as the SPM.

The basic HIPM modifications to the SPM are:

1. Add to the threshold health insurance needs (unsubsidized premium of the Basic Plan)

2. Add to resources any health insurance benefits received (any subsidies to, direct payments for, or direct provision of health insurance by government or employers, net of required premium payments) 
3. Cap the SPM's deduction of MOOP expenditures on care (non-premium MOOP) to address cost-sharing needs ${ }^{21}$

A household (SPM unit) is poor if HIPM resources are less than HIPM needs. Since health insurance resources cannot be used to purchase food or other necessities, the value of health insurance resources is never allowed to exceed the health insurance need.

\section{Health insurance needs and health insurance units}

Poverty status is determined for SPM units. But often health insurance resources and needs must be calculated for sub-units, because sub-units, not the entire SPM-unit, hold, or are eligible to hold, health insurance plans together. For example, a grandmother, mother and child may comprise an SPM-unit, with each separately insured: the grandmother on Medicare, the mother purchasing insurance on the exchange and the child receiving health insurance from a father outside the SPM-unit. Within each SPM unit, we assigned people to health insurance units (HIUs), based on their health insurance coverage and relationships to one another, as described in the Appendix. After determining health needs and resources for each HIU, as described below, we aggregated health insurance needs and resources to determine the SPM unit’s HIPM poverty status.

An HIU's health insurance needs are always the unsubsidized premium required for that HIU to purchase the Basic Plan. The Basic Plan is the second cheapest Silver plan available, for

\footnotetext{
${ }^{21}$ In this paper, we do not directly address needs for Over-the-Counter (OTC) expenditures. Sensitivity analysis in Korenman and Remler's (2016) Massachusetts pilot showed that the HIPM poverty rate increased by 0.3 percentage points when OTC expenses were deducted.
} 
everyone except those with Medicare coverage, for whom the Basic Plan is the cheapest available Medicare Advantage Prescription Drug plan. Appendix Section II describes the plan data and the calculation of Basic Plan premiums.

The HIPM poverty threshold is the sum of the SPM threshold (material needs) and health insurance needs. On average, for those in SPM-units with children, the health insurance need is $\$ 12,083$ and the SPM threshold is $\$ 27,662$, resulting in a HIPM threshold of $\$ 39,745$. HIPM thresholds for different family types are presented in the Section X.

\section{Net health insurance resources}

HIPM resources are the sum of health insurance resources and SPM resources, but without the deduction of MOOP. ${ }^{22}$ Those who receive health insurance benefits from government (Medicaid, CHIP and Medicare) and those who receive employer provided health insurance benefits, have health insurance resources equal to the value of the Basic Plan. For those who are required to pay out-of-pocket to receive their health insurance benefits, we deduct required out-of-pocket premium payments to calculate their net health insurance resources. ${ }^{23}$

The premise of the HIPM is that all needed health care is covered and made affordable by the Basic Plan and subsidies available for it. Therefore, if a family buys a more expensive plan than the Basic Plan, the HIPM should not deem it poorer. Consequently, we limit the premium MOOP deduction to that which would be required to purchase the Basic Plan—or a plan at least as good.

\footnotetext{
22 Taxes and necessary work expenses (including child care) are deducted.

${ }^{23}$ Since net insurance value is credited only for groups with insurance benefits, only those groups have premium MOOP deducted.
} 
For many families, that limit is simply the unsubsidized premium for the Basic Plan—its price in the market. Others, however, can obtain a plan as good as or better than the Basic Plan at a lower price (premium) and therefore they are assigned a lower premium MOOP deduction limit. For Medicaid beneficiaries who pay no out-of-pocket premium, we limit their premium deduction to zero.

For the individually insured who are eligible for a premium subsidy, health insurance resources equal the premium subsidy. Individually insured people who are not eligible for premium subsidies have zero health insurance resources. They must meet their health insurance needs from their income.

\section{Cost-sharing needs}

Health insurance is the primary health need. Nonetheless, to obtain needed health care, insured people must pay for cost-sharing, such as deductibles or co-insurance. Therefore, the need for cost-sharing must be incorporated. Several approaches to cost-sharing in a HIPM are possible and all have weaknesses (Korenman and Remler 2013 pp.23-25). Our treatment of cost-sharing is like the SPM's treatment of MOOP for health care, but we limit the non-premium MOOP deduction to a capped amount. The HIPM defines health needs, somewhat tautologically, as the care and conditions available under the Basic Plan. The HIPM should not designate a family as poorer because it spends more on health care than the Basic Plan’s cap on cost-sharing expenditures. Therefore, we limit the subtraction of nonpremium MOOP to whatever cap on total cost-sharing expenditures was available with the Basic Plan or the equivalent or better plan that the family has available (e.g., Medicaid). 
The plans available to individuals determine the applicable cost-sharing limit, such as $\$ 6350$ for an individual with a silver plan in 2014. Most importantly for the estimates presented below, most Medicaid beneficiaries have zero or low cost-sharing provisions, and all Medicaid beneficiaries have the sum of their premium and non-premium MOOP capped at $5 \%$ of household income (Medicaid.gov n.d.). Lower-income families who purchase Basic Plans on the exchanges have reduced out-of-pocket maxima, according to a schedule (Kaiser Family Foundation 2013). More generally, the plans available depend on geographic location, health insurance coverage, health insurance eligibility, employment status, immigration status, and other factors, as described fully in the Appendix, particularly Table A.1. 
HIPM compared to SPM

The following equations summarize the calculation of the HIPM:

HIPM Needs $=$ SPM Needs + HI Needs

HIPM Resources $=$ SPM Resources $($ pre MOOP deduction $)+$ Net HI Resources - Cost-sharing Needs

Where:

Net HI Resources $=$ Basic Plan Premium (BP)

- premium MOOP (up to cap)

Net HI Resources $=$ Premium subsidies

Net HI Resources $=0$

Cost-sharing Needs $=$ Nonpremium MOOP (up to cap)
For those with employer or government health insurance benefits

For those with individual insurance who are eligible for subsidies

For those who are uninsured and for those with individual insured who are not eligible for subsidies

Premium and nonpremium MOOP caps are determined by the available Basic Plan or an available plan as good or better. Appendix Table A.1 describes the health insurance resources, including premium MOOP deduction caps, and the nonpremium MOOP deduction caps for each health insurance type.

All else the same, adding a health insurance need increases the poverty threshold and therefore increases HIPM poverty relative to SPM poverty. Adding health insurance benefits to resources can meet, fully or partially, the higher needs threshold. Together, those two adjustments can never produce a HIPM poverty rate that is less than the SPM rate. However, the HIPM limit on MOOP deductions, the third factor, can make HIPM poverty less likely than SPM poverty. 
Accounting for the impact of Medicaid on poverty with the HIPM

To account for a social program's impact on the poverty rate, a counterfactual poverty rate is calculated by subtracting the program's benefit amount from household resources (e.g. Fox 2017). The impact of the benefit on the poverty rate is the difference between the counterfactual and actual poverty rates. This approach does not incorporate behavioral responses to removing social programs, such as changes in labor supply.

We estimated how much higher the child poverty rate would be if Medicaid were eliminated but nothing else changed. Our main estimates include the impact of CHIP together with Medicaid. However, we also present separate estimates for the impacts of CHIP, full-year Medicaid and part-year Medicaid.

Advantages of the HIPM

1. The HIPM incorporates health care needs through inclusion of an explicit health insurance need in the poverty threshold.

2. The HIPM need for health insurance also captures the need for ex ante risk reduction. (Korenman and Remler 2016, p. 28)

3. The HIPM can show the direct impact of Medicaid and other health insurance benefits on poverty, because health insurance needs are directly incorporated in the threshold and health insurance benefits are incorporated in resources in a way consistent with the threshold. 
4. The HIPM rate is one measure, the share of the population that does not have basic needs (health and material needs) met, rather than separate measures of material and health care deprivation.

5. Adding the full cost of health insurance to needs and resources in a poverty measure does not have the same problems as adding it to distributions of income (see Kaestner and Lubotsky, 2106 for a review). Even if health insurance costs are excessive for any reason (e.g., inefficiencies, low recipient valuation, an adversely selected risk pool), the HIPM adds the same amount to both resources and needs. The excessive amounts therefore cancel in poverty status calculations for anyone receiving health insurance benefits. While the excessive amounts do not cancel in HIPM status calculations for those not receiving health insurance benefits, HIPM status still accurately reflects that those individuals do not have resources to meet their health insurance needs, given how the health insurance system and market determine premiums.

6. The HIPM is a practical approach that can be implemented with CPS data used to calculate the SPM when augmented with information on premiums and cost-sharing for silver plans, Medicare-Advantage Prescription Drug plans and Medicaid.

7. Unlike the MCER, the HIPM adjusts automatically for changes in medical technology and health plan features that alter the relationship between expenditures and health status, insurance plans and other characteristics. 


\section{Disadvantages of the HIPM}

1. The HIPM can be implemented only under certain health system institutional conditions: guaranteed issue and community rating, or their equivalents. ${ }^{24}$ Without these provisions, it is not possible to define an amount of money needed to purchase a basic plan (e.g., those with a serious pre-existing condition may not be able to purchase a plan that covers care for that condition at any price).

2. Excessive costs of individually-purchased health insurance (due to inefficiencies, adversely selected risk pool, or low recipient value) inflate the impact of Medicaid (and other health insurance benefits), both absolutely and relative to non-health-insurance programs.

3. HIPM validity requires that health insurance is considered a basic need. The political debates in the US make clear that disagreement continues about this assumption. However, there is less disagreement that health care is a need. We know of no consistent and valid approach to including health care needs in an overall poverty measure that can assess the impact of health insurance benefits on poverty.

4. HIPM cost-sharing needs have potential errors in both directions. Cost-sharing needs are calculated as actual MOOP expenditures on care, up to the available cap. To the extent that costsharing provisions deter needed care, cost-sharing needs are under-estimated. On the other hand, the HIPM deducts all spending up to the non-premium MOOP cap, even if that spending is on care that would be deemed unnecessary or excessive. In such cases, HIPM would overstate

\footnotetext{
${ }^{24}$ While most Americans were subject to these rules only after 2014, Americans aged 65 and older have effectively had guaranteed issue and community rating since 1965 due to the Medicare program.
} 
implicit cost-sharing needs. ${ }^{25}$ Because the non-premium MOOP cap limits the size of these potential errors, they are another institutional feature that promotes validity of the HIPM.

5. The HIPM cannot calculate the direct impact of ACA cost-sharing reduction subsidies because cost-sharing needs are not an explicit need incorporated in the threshold. However, cost-sharing reduction subsidies will reduce HIPM poverty indirectly, by reducing non-premium MOOP expenditures. ${ }^{26} 27$

\section{Results: Impact of Medicaid on Child Health-Inclusive Poverty}

In this section, we present poverty rates for children and Medicaid impacts on child poverty, deep poverty and near poverty, all using the Health Inclusive Poverty Measure HIPM. The HIPM child poverty rate and corresponding impacts of Medicaid, means-tested benefits and tax credits are similar to those reported in Remler, Korenman and Hyson (2017).

HIPM Thresholds. The HIPM threshold is the sum of the SPM threshold and the health insurance need for the family (SPM unit), as described in the HIPM Methods section and Appendix. Table 1 displays average HIPM thresholds, SPM thresholds and health insurance needs for families of different sizes and age composition.

\footnotetext{
${ }^{25}$ While no widely accepted conceptual definition of needed care exists, much less an empirical definition, our approach considers as "needed" whatever care people would get with the Basic Plan.

${ }^{26}$ These indirect impacts could be estimated by estimating counterfactual nonpremium MOOP expenditures, as in Sommers and Oellerich (2013).

${ }^{27}$ The treatment of cost-sharing is a disadvantage for those who believe that the health insurance need for lower income people should be a richer plan than the Silver plan, such as a Medicaid plan with little or no cost-sharing. However, there are practical problems implementing such a need consistently. A Medicaid plan could easily and consistently be designated as both need and resource for those who actually receive Medicaid, but not for those who are otherwise similar but do not have Medicaid. If Medicaid is made their need and they spend money out-of-pocket on care, then inconsistencies arise from either deducting or not deducting their non-premium MOOP. Deducting such expenditures from resources basically counts their cost-sharing (and care) needs twice: once in the insurance plan that does not require cost-sharing and again through deduction. Not deducting those expenditures misses how people are truly made worse off in their ability to meet care and/or material needs, and misses how they are poorer than healthy people in otherwise identical circumstances.
} 
The average HIPM threshold for all persons in families with children is $\$ 39,745$, of which, the average material need (SPM threshold) is $\$ 27,662$ and the average health insurance need is $\$ 12,083$. Thus, on average the insurance need is 30 percent of the HIPM threshold. For a family with one adult and two children, the average HIPM threshold is $\$ 27,727$, of which $\$ 6,949$ is the health insurance need. For this family type, the health insurance need is 25 percent of the HIPM threshold. Differences in threshold values across family types show the much higher cost of health insurance for adults than for children.

HIPM resources. The HIPM methods section and Appendix explain that HIPM resources begin with SPM resources before the MOOP subtraction and then add a value for any health insurance benefits received, net of capped, required premium payments. The uninsured have no health insurance resources. Like the SPM, the HIPM treats the need for cost sharing—nonpremium MOOP—as a subtraction from resources, though it caps that subtraction.

HIPM Child Poverty Rates. Table 2 shows the proportion of children below the HIPM poverty, deep poverty and near poverty thresholds. The HIPM threshold for deep poverty for a family is the family's health insurance need plus one-half the SPM threshold. The threshold for near-poverty is the health insurance need plus one-and-one-half times the SPM threshold.

The HIPM child poverty rate in 2014 was $18.4 \%$. The corresponding SPM child poverty rate for this sample was $16.0 \%$; before the SPM MOOP deduction, it was 13.0\%. (The SPM rates are not shown in Table 2.) The higher HIPM rate reflects the ability of the HIPM to capture the direct impact on child poverty of the unmet need for health insurance. The HIPM deep poverty rate was 5.8\%, and the proportion of children below the HIPM near poverty threshold was 38.5\% (Table 2, row 1). 
Medicaid Impacts. To account for the impact of Medicaid on poverty, we computed counterfactual HIPM poverty rates by subtracting a value for Medicaid from the resources of families with Medicaid recipients. ${ }^{28}$ The impact of Medicaid on poverty is the difference between the counterfactual and actual poverty rate.

When Medicaid is removed from resources, all else the same, the HIPM child poverty rate rises from $18.4 \%$ (row 1 ) to $23.7 \%$ (row 2 ) for an impact of 5.3 percentage points (row 5). For comparison, we also computed estimates for the impact of all non-health cash and in-kind means-tested benefits (TANF, SNAP, WIC, SSI, school meal programs, and housing and energy subsidies) and for federal refundable tax credits (EITC and CTC). The 5.3 percentage point reduction of child poverty from Medicaid is greater than the combined impact of all means-tested cash and in-kind benefits (4.4 points), though somewhat smaller than the impact of federal tax credits targeted to families with children (6.5 points).

Medicaid has a smaller impact on the proportion of children below the HIPM deep or near poverty thresholds: 3.2 and 3.1 percentage points, respectively (Table 2, row 5). For deep poverty, the impact of Medicaid is smaller than the impact of other means-tested benefits but larger than the impact of tax credits. In contrast, for the proportion below the near-poverty threshold, Medicaid has a larger impact than means-tested benefits and approximately the same impact as tax credits. This pattern results from the large transfers through tax credits to families with earnings, who are more likely to have incomes above half the poverty line, and the targeting of means-tested benefits to the poorest families (Moffitt 2015). Medicaid's impact appears to be

\footnotetext{
${ }^{28}$ For this calculation, we did not subtract the Medicaid benefits of dual Medicaid-Medicare eligibles.
} 
somewhat more evenly spread across the lower-end of income distribution (among families with children).

As we noted in the discussion of the HIPM approach, these Medicaid impact estimates do not capture the impact of Medicaid's generous cost-sharing. In principle, the HIPM could also be used to estimate that impact by estimating counterfactual non-premium MOOP (see Sommers and Oellerich, 2013).

The estimate of the impact of Medicaid on HIPM poverty in Table 2 included the impact of fullyear Medicaid, pro-rated part-year Medicaid and CHIP. Table 3 shows the disaggregation of this impact. Nearly $90 \%$ (4.7 out of 5.3 percentage points) of the Medicaid impact on HIPM child poverty is attributable to full-year Medicaid (Table 3, rows 8, 9 and 10).

Results presented so far assume that the health insurance need is the unsubsidized premium of the second-low-cost Silver plan in the ACA rating area where the family resides. As explained in the Methods section, a family’s health insurance resources are always less than or equal to this need. For example, if the family is covered by a Medicaid plan with no required premium payments, the health insurance need is fully met and the value of health insurance resources is also the second low-cost Silver plan premium.

How sensitive are our results to the Basic Plan premium used to value health insurance in needs and resources? Table 4 shows the sensitivity of results to varying the value of the health insurance. Specifically, we set the health insurance need to either $100 \%$, $75 \%$ or $125 \%$ of the unsubsidized premium of the second low-cost Silver plan and also adjusted all health insurance 
resources consistently. ${ }^{29}$ Column 1 of Table 4 reproduces the HIPM child poverty rate (18.4\%) and Medicaid impact (5.3 percentage points) from Table 2, which used 100\% of the premium of the second low-cost Silver plan. Comparing results across columns 1, 2, and 3 reveals that HIPM rates and Medicaid impacts are modestly affected by these variations in the insurance value. ${ }^{30}$ The Medicaid impact on child poverty falls by about one percentage point when the health insurance need is $75 \%$ of the silver plan, and rises by about 1 percentage point when the health insurance need is $125 \%$ of the silver plan. The modest sensitivity of results stems from the use of the same value of insurance (e.g., 125\% Silver plan premium) for the health insurance need in the threshold and for the (maximum) value of health insurance resources. Medicaid fully meets the health insurance needs of Medicaid recipients, whatever the specific dollar value assigned to that need.

So far, we have assumed that no health insurance resources are available either to the uninsured or to Medicaid recipients in the counterfactual situation in which Medicaid is subtracted from resources to estimate Medicaid impacts. Table 5 shows the sensitivity of results to two different assumptions about the availability of health insurance resources to the uninsured or to Medicaid beneficiaries in the "Medicaid counterfactual."

The first alternative credits the uninsured with any ACA premium subsidies they would be eligible to receive, if they were to purchase insurance. This approach is motivated by the ACA mandate to purchase insurance, just as laws mandate tax payments, and the Census practice of imputing income taxes paid and tax credits received on the basis of income (Short, Donahue and

\footnotetext{
${ }^{29}$ The choice of a new health insurance need requires a decision about whether the benchmark plan used to determine premium subsidies also changes. For these calculations, we have changed the benchmark plan to be the new health insurance need and adjusted premium subsidies accordingly.

${ }^{30}$ The sensitivity analyses discussed here and shown in Table 4 differ from those in the previous version of this report due to the correction of a coding error.
} 
Lynch 2012). In this first alternative we continue to assume that Medicaid beneficiaries have no health insurance resources in the counterfactual situation. The resulting poverty rates and Medicaid impacts, shown in column 2 of Table 5, are very similar to those presented in Table 2, and summarized in column 1 of Table 5. In particular, crediting the uninsured with ACA subsidies for which they would be eligible lowers the HIPM child poverty rate by one-half percentage point, from $18.4 \%$ to $17.9 \%$, and leaves the Medicaid impact unchanged at 5.3 percentage points.

Our second sensitivity analysis assumes that the uninsured have access to free care and that current Medicaid beneficiaries would also have access to free care if their Medicaid benefits were removed (the counterfactual for "Medicaid losers"). The implicit insurance value of free care is set to $60 \%$ of the value of the unsubsidized premium of the second-cheapest Silver plan. The 60\% figure is our calculation based on results reported in Finkelstein, Hendren and Luttmer (2016, Table 1, columns II and III) from the Oregon Health Insurance experiment; it is the ratio of the actuarial value of free care received by the randomly-assigned control group to the actuarial value of Medicaid-funded care received by randomly-assigned Medicaid treatment group (see discussion in section VIII for additional details). ${ }^{31}$

The results are sensitive to the assumption that the uninsured and "Medicaid losers" would receive substantial free care. The HIPM poverty rate is $16.6 \%$ rather than $18.4 \%$, and the impact of Medicaid falls from 5.3 percentage points to 2.2. This sensitivity is not surprising given the large value of implicit insurance through free care that is assumed to replace Medicaid in the counterfactual situation in which all Medicaid recipients lose their benefits. Of course, if all

\footnotetext{
${ }^{31}$ Specifically, it is the ratio of (mean medical spending minus mean out-of-pocket spending) of "control group compliers" to "treatment group compliers" or $(2721-569) / 3600=0.60$.
} 
Medicaid were eliminated, sustaining that level of free care would require significant additional funding. 
XI. Figure 1: Poverty Measure Concepts: Official, Supplemental and Health Inclusive

\begin{tabular}{|c|c|c|c|}
\hline & $\begin{array}{l}\text { Official } \\
\text { Poverty Measure }\end{array}$ & Supplemental Poverty Measure & Health Inclusive Poverty Measure \\
\hline Measurement Units & $\begin{array}{l}\text { Families or unrelated } \\
\text { individuals }\end{array}$ & $\begin{array}{l}\text { Families, including any coresident unrelated children who are } \\
\text { cared for by the family and any cohabiters and their relatives, or } \\
\text { unrelated, noncohabiting individuals }\end{array}$ & Same as $\mathrm{SPM}^{\mathrm{i}}$ \\
\hline Non-Health Needs & $\begin{array}{l}\text { Three times cost of } \\
\text { minimum food diet in } \\
1963^{\text {ii }}\end{array}$ & $\begin{array}{l}\text { The mean of expenditures on food, clothing, shelter, and utilities } \\
\text { (FCSU) over all two-child consumer units in the 30th to 36th } \\
\text { percentile expenditure range multiplied by } 1.2\end{array}$ & Same as SPM measure of non-health needs \\
\hline $\begin{array}{l}\text { Adjustments to } \\
\text { Non-health Needs }\end{array}$ & $\begin{array}{l}\text { Vary by family size, } \\
\text { composition, and age of } \\
\text { householder }\end{array}$ & $\begin{array}{l}\text { Geographic adjustments for differences in housing costs by tenure } \\
\text { and a three-parameter equivalence scale for family size and } \\
\text { composition }\end{array}$ & Same as SPM \\
\hline $\begin{array}{l}\text { Updating Non- } \\
\text { health Needs }\end{array}$ & $\begin{array}{l}\text { Consumer Price Index: } \\
\text { all items }\end{array}$ & 5-year moving average of expenditures on FCSU & Same as SPM \\
\hline $\begin{array}{l}\text { Health Insurance } \\
\text { Needs }\end{array}$ & $\begin{array}{l}\text { Small amount implicit in } \\
\text { the } 3 \mathrm{X} \text { multiplier }\end{array}$ & $\begin{array}{l}\text { Explicit: None } \\
\text { Implicit: All out-of-pocket expenditures on insurance (premium } \\
\text { MOOP) [because deducted from resources as a nondiscretionary } \\
\text { expense] }\end{array}$ & $\begin{array}{l}\text { Explicit: Unsubsidized Premium of Basic Health } \\
\text { Insurance Plan }\end{array}$ \\
\hline $\begin{array}{l}\text { Cost-sharing and } \\
\text { Uncovered Health } \\
\text { Care Needs }\end{array}$ & $\begin{array}{l}\text { Small amount implicit in } \\
\text { the } 3 \mathrm{X} \text { multiplier }\end{array}$ & $\begin{array}{l}\text { Explicit: None } \\
\text { Implicit: All out-of-pocket expenditures on care (non-premium } \\
\text { MOOP) [because deducted from resources as a nondiscretionary } \\
\text { expense] }\end{array}$ & $\begin{array}{l}\text { Explicit: None } \\
\text { Implicit: Capped out-of-pocket expenditures on } \\
\text { care (non-premium MOOP up to the cap } \\
\text { available with Basic Plan) [because deducted } \\
\text { from resources] }\end{array}$ \\
\hline $\begin{array}{l}\text { Non-Health } \\
\text { Resources }\end{array}$ & $\begin{array}{l}\text { Gross before-tax cash } \\
\text { income }\end{array}$ & $\begin{array}{l}\text { Sum of cash income, plus noncash benefits that families can use } \\
\text { to meet their FCSU needs minus taxes (or plus tax credits), minus } \\
\text { work expenses and child support paid to another household } \\
\text { minus out-of-pocket medical care and insurance and Over-the- } \\
\text { counter expenses (MOOP) }\end{array}$ & $\begin{array}{l}\text { SPM Resource Measure but without the MOOP } \\
\text { subtraction }\end{array}$ \\
\hline $\begin{array}{l}\text { Health Insurance } \\
\text { Resources }\end{array}$ & None & None & $\begin{array}{l}\text { For those who get private or public health } \\
\text { insurance benefits: Unsubsidized premium of } \\
\text { Basic Plan minus actual premium MOOP } \\
\text { (limited to premium MOOP necessary to obtain } \\
\text { Basic Plan). } \\
\text { For those eligible for premium subsidies: } \\
\text { subsidy value. }\end{array}$ \\
\hline
\end{tabular}

Source: Korenman and Remler (2016, Table 1). The OPM and SPM descriptions are partly based on Short (2013, page 3).

${ }^{\mathrm{i}}$ However, health insurance needs \& resources are determined for Health Insurance Units, subunits of the SPM unit, then aggregated to SPM unit

${ }^{\text {ii }}$ A small amount of out of pocket expenditures for health insurance and care is captured by the OPM needs threshold 


\section{Tables}

Table 1: Average SPM \& HIPM Thresholds ${ }^{1}$ and Health Insurance Need, by Number of Adults and Children Present, 2014 Families (SPM Units) With at Least One Child Under age 18

\begin{tabular}{|l|c|c|c|c|}
\hline & $\begin{array}{c}\text { SPM } \\
\text { Threshold }\end{array}$ & $\begin{array}{c}\text { Health } \\
\text { Insurance } \\
\text { Need }\end{array}$ & $\begin{array}{c}\text { HIPM }^{3} \\
\text { Threshold }\end{array}$ & $\begin{array}{c}\text { Sample } \\
\text { Size }\end{array}$ \\
\hline & $(1)$ & $(2)$ & $(3)=(1)+(2)$ & $(4)$ \\
\hline All SPM units with children & $\$ 27,662$ & $\$ 12,083$ & $\$ 39,745$ & 106,946 \\
\hline & & & & \\
\hline 1 adult, 1 child SPM & $\$ 17,540$ & $\$ 5,462$ & $\$ 23,002$ & 3,973 \\
\hline 1 adult, 2 children SPM & $\$ 20,779$ & $\$ 6,949$ & $\$ 27,727$ & 4,046 \\
\hline 1 adult, $3+$ children SPM & $\$ 25,688$ & $\$ 8,660$ & $\$ 34,348$ & 3,281 \\
\hline & & & & \\
\hline 2 adults, 1 child SPM & $\$ 22,533$ & $\$ 8,915$ & $\$ 31,448$ & 17,715 \\
\hline 2 adults, 2 children SPM & $\$ 25,770$ & $\$ 10,415$ & $\$ 36,185$ & 27,292 \\
\hline 2 adults, $3+$ children SPM & $\$ 29,517$ & $\$ 11,927$ & $\$ 41,444$ & 21,149 \\
\hline & & & & \\
\hline $3+$ adults, $1+$ child SPM & $\$ 33,696$ & $\$ 17,522$ & $\$ 51,217$ & 29,490 \\
\hline
\end{tabular}

Notes:

1. The average thresholds are the threshold of the average person's SPM-unit (i.e., the average is taken over all persons in SPM-unit with children present). Means are weighted by ASEC (March Supplement) sample weights.

2. SPM: Supplemental Poverty Measure

3. HIPM: Health Inclusive Poverty Measure 
Table 2: HIPM Poverty Rates and Impacts of Medicaid and Selected Other Transfers on Rates of HIPM Poverty, Deep Poverty \& Near Poverty for Children ${ }^{1}, 2014$

\begin{tabular}{|c|c|c|c|c|}
\hline $\begin{array}{l}\text { Row } \\
\text { Number }\end{array}$ & Poverty Rates (percent) & $\begin{array}{l}\text { HIPM } \\
\text { Poor }\end{array}$ & $\begin{array}{c}\text { HIPM } \\
\text { Deep Poor }^{2}\end{array}$ & $\begin{array}{c}\text { HIPM } \\
\text { Poor or Near } \\
\text { Poor }^{3}\end{array}$ \\
\hline 1 & HIPM rate & $18.4 \%$ & $5.8 \%$ & $38.5 \%$ \\
\hline 2 & HIPM rate, if subtract Medicaid ${ }^{4}$ only from resources & $23.7 \%$ & $8.9 \%$ & $41.6 \%$ \\
\hline 3 & HIPM rate, if subtract means-tested benefits ${ }^{5}$ only from resources & $22.9 \%$ & $9.8 \%$ & $40.8 \%$ \\
\hline 4 & HIPM rate, if subtract tax credits ${ }^{6}$ only from resources & $24.9 \%$ & $8.6 \%$ & $41.7 \%$ \\
\hline & \multicolumn{4}{|l|}{ Program Impacts (percentage points) ${ }^{4}$} \\
\hline $5=2-1$ & Medicaid $^{5}$ & 5.3 & 3.2 & 3.1 \\
\hline $6=3-1$ & Means-tested benefits $^{6}$ & 4.4 & 4.0 & 2.3 \\
\hline $7=4-1$ & Tax credits $^{7}$ & 6.5 & 2.8 & 3.3 \\
\hline
\end{tabular}

Notes:

1. Children are under age 18.

2. HIPM Deep Poverty Threshold $=$ Health Insurance need $+50 \%$ of SPM threshold

3. HIPM Near Poverty Threshold $=$ Health Insurance need $+150 \%$ of SPM threshold

4. Impacts are differences in percentage points. Due to rounding, the impacts presented in rows 5 to 7 sometimes differ by 0.1 percentage point from the difference between the corresponding rates presented in rows 1 through 4 .

5. Medicaid includes full-year, part year (pro-rated), and CHIP. See Table 3 for the contribution of each to the overall Medicaid effect.

6. Means-tested benefits include: TANF, SNAP, WIC, SSI, school meal programs, and housing and energy subsidies.

7. Tax credits include: the federal EITC and CTC. 
Table 3: HIPM Poverty Rates and Impacts of Medicaid and Selected Transfers for Children, 2014

\begin{tabular}{|c|c|c|}
\hline $\begin{array}{l}\text { Row } \\
\text { number }\end{array}$ & Poverty Rates (percent) & $\begin{array}{c}\text { HIPM } \\
\text { Poverty }\end{array}$ \\
\hline 1 & HIPM rate & $18.4 \%$ \\
\hline 2 & HIPM: subtract Medicaid (FY, PY) \& CHIP & $23.7 \%$ \\
\hline 3 & HIPM: subtract FY Medicaid only & $23.1 \%$ \\
\hline 4 & HIPM: subtract PY Medicaid only & $18.7 \%$ \\
\hline 5 & HIPM: subtract CHIP only & $18.9 \%$ \\
\hline 6 & HIPM: subtract means tested benefits only & $22.9 \%$ \\
\hline \multirow[t]{2}{*}{7} & HIPM: subtract tax credits only & $24.9 \%$ \\
\hline & Program Impact (percentage points) & \\
\hline $8=2-1$ & Medicaid FY \& PY, CHIP & 5.3 \\
\hline $9=3-1$ & FY Medicaid & 4.7 \\
\hline $10=4-1$ & PY Medicaid & 0.2 \\
\hline $11=5-1$ & CHIP & 0.4 \\
\hline $12=6-1$ & Means-tested benefits & 4.4 \\
\hline $13=7-1$ & Tax credits & 6.5 \\
\hline & Number of observations (children) & 50398 \\
\hline
\end{tabular}

See notes to Table 2 for definitions. 
Table 4: HIPM Poverty Rates and Medicaid Impacts, Children, 2014: Sensitivity to Value of Basic Plan Premium ${ }^{1}$

\begin{tabular}{|l|c|c|c|}
\hline & $\begin{array}{c}\text { HIPM Poverty } \\
\text { HIPM Poverty } \\
\text { Insurance Value }= \\
\text { Silver Plan Premium }\end{array}$ & $\begin{array}{c}\text { HIPM Poverty } \\
\text { Insurance Value }= \\
75 \% \text { of Silver Plan } \\
\text { Premium }\end{array}$ & $\begin{array}{c}\text { Insurance Value }= \\
125 \% \text { of Silver } \\
\text { Premium }\end{array}$ \\
\hline Poverty Rates (percent) & $(1)$ & $(2)$ & $13)$ \\
\hline HIPM rate & $18.4 \%$ & $17.5 \%$ & $25.9 \%$ \\
\hline HIPM: subtract Medicaid (FY, PY \& CHIP) & $23.7 \%$ & $21.5 \%$ & 6.5 \\
\hline \multicolumn{3}{|l|}{} \\
\hline Program Impacts (percentage points) & 5.3 & 4.2 & 50398 \\
\hline Medicaid (FY, PY, CHIP) & 50938 & 50398 & \\
\hline Number of observations (children) &
\end{tabular}

${ }^{1}$ The figures in columns (2) and (3) differ from those in the previous version of this report due to the correction of a coding error. 
Table 5: HIPM Poverty Rates and Medicaid Impacts Under Alternative Assumptions About Health Insurance Resources Available to the Uninsured, and to Medicaid Recipients in the Counterfactual State for Children, 2014

\begin{tabular}{|c|c|c|c|}
\hline & HIPM Poverty & $\begin{array}{c}\text { HIPM Poverty: } \\
\text { Uninsured Get ACA } \\
\text { Premium Subsidies }\end{array}$ & $\begin{array}{c}\text { HIPM Poverty: } \\
\text { Uninsured and } \\
\text { Medicaid Counterfactual } \\
\text { Get Free Care }\end{array}$ \\
\hline Poverty Rates (percent) & $(1)$ & $(2)$ & (3) \\
\hline HIPM rate & $18.4 \%$ & $17.9 \%$ & $16.6 \%$ \\
\hline HIPM: subtract Medicaid (FY, PY \& CHIP) & $23.7 \%$ & $23.1 \%$ & $18.8 \%$ \\
\hline \multicolumn{4}{|l|}{ Program Impact (percentage points) } \\
\hline Medicaid (FY, PY, CHIP) & 5.3 & 5.3 & $2.2 \%$ \\
\hline \multicolumn{4}{|l|}{ Assumptions about health insurance resources } \\
\hline Uninsured & None & $\begin{array}{l}\text { ACA Premium } \\
\text { Subsidies }\end{array}$ & Free Care \\
\hline Medicaid Counterfactual & None & None & Free Care \\
\hline Number of observations (children) & 50938 & 50398 & 50398 \\
\hline
\end{tabular}

1. Adds a value to resources for the ACA premium subsidies that the uninsured would receive if they were to buy insurance.

2. Adds a value of free care to the resources of the uninsured and to Medicaid recipients in the counterfactual to represent a replacement of Medicaid with free care. The value of free care is set to $60 \%$ of the unsubsidized premium of the second-low-cost Silver plan in the family's ACA rating area. See text for discussion. 


\section{References}

Abramowitz, Joelle, Brett O’Hara and Darcy Steeg Morris. 2017. Risking Lie and Limb: Estimating a Measure of Medical Care Economic Risk, and Considering Its Implications. Health Economics 26: 469-485.

Antonisse, Larisa. Rachel Garfield, Robin Rudowitz, and Samantha Artiga. 2017. The Effects of Medicaid Expansion under the ACA: Updated Findings from a Literature Review. Issue Brief. Kaiser Family Foundation. September 25. https://www.kff.org/medicaid/issue-brief/the-effectsof-medicaid-expansion-under-the-aca-updated-findings-from-a-literature-review-september2017/

Ben-Shalom, Yonatan, Robert Moffitt, and John Karl Scholz. 2012. An Assessment of the Effectiveness of Antipoverty Programs in the United States. In Philip N. Jefferson, ed. The Oxford Handbook of the Economics of Poverty. New York: Oxford University Press.

Burkhauser, R.V., J. Larrimore and K.I. Simon. 2012. "A “Second Opinion” on the Economic Health of the American Middle Class" National Tax Journal, 65: 7-32.

Burkhauser, R.V., J. Larrimore and K. Simon. 2013. Measuring the impact of valuing health insurance on levels and trends in inequality and how the Affordable Care Act of 2010 could affect them. Contemporary Economic Policy 31(4): 779-794.

Burtless, Gary and Sarah Siegel. 2004. Medical Spending, Health Insurance, and Measurement of American Poverty. In Race, Poverty, and Domestic Policy, edited by C. Michael Henry. New Haven: Yale University Press, 117-154.

Citro, Constance F. and Robert T. Michael, eds. 1995. Measuring Poverty: A New Approach. National Research Council of the National Academy of Sciences. Washington DC: National Academy Press.

Cogan, John F. 1995 Dissent. Appendix A, in Citro, C. and R. T. Michael, eds. 1995. Measuring Poverty: A New Approach. National Research Council of the National Academy of Sciences. National Academy Press.

Congressional Budget Office. 2011. Trends in the Distribution of Household Income Between 1979 and 2007 CBO Publication 4031. October 25. https://www.cbo.gov/publication/42729

Congressional Budget Office (CBO). 2012. The Distribution of Household Income and Federal Taxes, 2008 and 2009. http://www.cbo.gov/sites/default/files/cbofiles/attachments/43373-06-11HouseholdIncomeandFedTaxes.pdf 
Finkelstein, Amy, Neale Mahoney, and Matthew J. Notowidigdo. 2017. What Does (Formal) Health Insurance Do, and For Whom? NBER Working Paper 23718. August.

Finkelstein, Amy, Nathaniel Hendren, and Mark Shepard. 2017. Subsidizing health insurance for low-income adults: Evidence from Massachusetts. NBER Working Paper No. 23668. August.

Finkelstein, Amy, Nathaniel Hendren, and Erzo F.P. Luttmer. 2016. The Value of Medicaid: Interpreting Results from the Oregon Health Insurance Experiment. November. Revision of NBER Working 21308.

Foster, Ann C. 2016. "Household healthcare spending in 2014,” Beyond the Numbers: Prices \& Spending, 5(13) (U.S. Bureau of Labor Statistics, August. https://www.bls.gov/opub/btn/volume5/household-healthcare-spending-in-2014.htm

Fox, Liana. 2017. The Supplemental Poverty Measure: 2016. Current Population Report P60261. US Census Bureau, September.

Garner, Thesia I. and Kathleen S. Short. 2010. Identifying the poor: Poverty Meaurement for the U.S from 1966 to 2005. Review of Income and Wealth 56(2): 237-258.

Garthwaite, Craig, Tal Gross and Matthew J. Notowidigdo. 2015. Hospitals as Insurers of Last Resort. National Bureau of Economic Research working paper no. 21290.

Hendren, Nathaniel. 2017. Measuring Ex-Ante Welfare in Insurance Markets. August. Department of Economics. Harvard University.

National Academies of Sciences, Engineering, and Medicine. 2019. A Roadmap to Reducing Child Poverty. Washington, DC: The National Academies Press. https://doi.org/10.17226/25246. Accessed February 28, 2019.

Hirth, Richard A., Sebastian Calonico, Teresa B. Gibson, Helen Levy, Jeffrey Smith and Anup Das. 2016. "Long Term Health Spending Persistence among the Privately Insured in the US" Fiscal Studies 37(304): 749-783.

Hoynes, Hilary W., Marianne E. Page \& Ann Huff Stevens. 2006. Poverty in America: Trends and Explanations. Journal of Economic Perspectives 20(1): 47-68.

Kaestner, Robert and Darren Lubotsky. 2016. Health Insurance and Income Ineqality Journal of Economic Perspectives. 30 (2): 53-78.

Kaiser Family Foundation. 2013. Summary of the Affordable Care Act. https://www.kff.org/health-reform/fact-sheet/summary-of-the-affordable-care-act/ Accessed October 1, 2017. 
King, Miriam, Steven Ruggles, J. Trent Alexander, Sarah Flood, Katie Genadek, Matthew B. Schroeder, Brandon Trampe, and Rebecca Vick. 2010. Integrated Public Use Microdata Series, Current Population Survey: Version 3.0. [Machine-readable database]. Minneapolis: University of Minnesota.

Korenman, Sanders, Dahlia K. Remler and Rosemary T. Hyson. 2019. Who are the elderly poor and how much are they helped by social and health policies? Paper presented to the 2019 Meetings of the Population Association of America. Austin, TX. April.

Korenman, Sanders and Dahlia K. Remler. 2013. Rethinking elderly poverty: time for a health inclusive poverty measure? NBER Working Paper No. 18900. March.

Korenman, Sanders D. \& Dahlia K. Remler 2016. Including health insurance in poverty measurement: the impact of Massachusetts health reform on poverty. Journal of Health Economics 50: 27-35.

MACPAC (Medicaid and CHIP Payment and Access Commission). 2016. MACStats: Medicaid and CHIP Data Book. December. https://www.macpac.gov/macstats/

Medicaid.gov. n.d. Cost Sharing Our of Pocket Costs. https://www.medicaid.gov/medicaid/costsharing/out-of-pocket-costs/index.html October 1, 2017.

Meier S. and B. Wolfe. 2012. Conceptual Framework for Measuring Medical Care Economic Risk. In Medical Care Economic Risk: Measuring Financial Vulnerability from Spending on Medical Care. Panel on Measuring Medical Care Risk in Conjunction with the New Supplemental Income Poverty Measure, M.J.

Meier, Sarah K. 2016. Examining risk classification strategies for the development of a measure of medical care economic risk in the United States. Journal of Economic and Social Measurement 41: 289-305.

Meyer, Bruce D. and James X. Sullivan. 2012. Winning the War: Poverty from the Great Society to the Great Recession. Brookings Papers on Economic Activity, Fall: 133-200.

Meyer, Bruce and James X. Sullivan. 2013. Winning the War: Poverty from the Great Society to the Great Recession NBER Working Paper 18718, on-line appendix: www.nber.org/dataappendix/w18718/.

Mitchell, Emily. 2016. Concentration of Health Expenditures in the US Civilian, Noninstitutionalized population, 2014. AHRQ Statistical Brief 497. https://meps.ahrq.gov/data_files/publications/st497/stat497.pdf

Moffitt, Robert A. (2016). "Introduction” Economics of means tested transfer programs in the United States, Volume 1 edited by Robert A. Moffitt. Chicago: University of Chicago Press. 
Moffitt Robert A. 2015. The deserving poor, the family, and the U.S. welfare system. Demography 52(3):729-49.

Moon, Marilyn. 1993. Incorporating Health Issues in the Measurement of Poverty. Urban Institute.

National Research Council. 2005. Experimental Poverty Measures: Summary of a Workshop. Washington, DC: The National Academies Press. https://doi.org/10.17226/11166

Norris, Louise. 2019. Can recent immigrants to the United States get health coverage if they are over 65? https://www.medicareresources.org/faqs/can-recent-immigrants-to-the-united-statesget-health-coverage-if-theyre-over-65/. January 23.

Nyman, John A. 2003. The Theory of Demand for Health Insurance. Stanford, CA: Stanford University Press.

Nyman, John. 2004. “Is Moral Hazard Inefficient?” Health Affairs 23(5): 194-199.

O’Grady and G.S. Wunderlich, Eds. 2012. Committee on National Statistics, Division of Behavioral and Social Sciences and Education, and Board on Health Care Services, Institute of Medicine. Washington, DC: The National Academies Press.

Remler, Dahlia K., Sanders D. Korenman and Rosemary T. Hyson. 2017. Estimating the Effects of Health Insurance and Other Social Programs On Poverty Under the Affordable Care Act. Health Affairs 36(10): 1828-1837 October 2.

Scholz, John Karl, Robert Moffitt \& Benjamin Cowan. 2009. Trends in income support. In Maria Cancian and Sheldon Danziger, eds. Changing Poverty, Changing Policies New York: Russell Sage Foundation, pp. 203-241.

Short, Kathleen S. 2011. The Supplemental Poverty Measure: Examining the Incidence and Depth of Poverty in the U.S. Taking Account of Taxes and Transfers. US Census Bureau SEHSD working paper \# 2011-20 June 3.

Short, Kathleen S. 2013. The Research Supplemental Poverty Measure: 2012. Current Population Reports P60-247, U.S. Census Bureau. November.

Short, Kathleen, Dennis Donahue \& George Lynch. 2012. EITC Estimates in the CPS ASEC Simulations of After-Tax Income Hispanic Population. SEHSD Working Paper \# 2012-19. August.

Smeeding, Timothy M. 1977. The Antipoverty Effectiveness of In-Kind Transfers. Journal of Human Resources 12(3): 360-378 
Smeeding, Timothy M. 1982. Alternative Methods for Valuing Selected In-Kind Transfer Benefits and Measuring Their Effects on Poverty. Technical Paper No. 50. Bureau of the Census. Washington DC: Bureau of the Census.

Society of Actuaries. 2016. “Accuracy of Claims Based Risk Scoring Models.” https://www.soa.org/.../research-2016-accuracy-claims-based-risk-scoring-models.pdf

Sommers, Benjamin D. and Donald Oellerich. 2013. The Poverty-Reducing Effect of Medicaid. Journal of Health Economics 32: 816-832.

Sommers, Benjamin D., Atul A. Gawande, and Katherine Baicker. 2017. Health Insurance Coverage and Health-What the Recent Evidence Tells Us. New England Journal of Medicine 377: 586-593.

United Nations. 1948. The Universal Declaration of Human Rights. www.un.org/en/universaldeclaration-human-rights.

US Census. 1988a. Estimates of Poverty Including the Value of Noncash Benefits: 1987. Technical Paper 58. Washington DC: USGPO.

US Census. 1988b. Measuring the Effects of Benefits and Taxes on Income and Poverty, 1986. P60-164- RD-1. Washington, DC: USGPO.

US Census. 1993. Current Population Reports, Series P60-186RD, Measuring the Effect of Benefits and Taxes on Income and Poverty: 1992, Washington, DC: USGPO.

Winship, Scott (2016). Poverty After Welfare Reform. Manhattan Institute Report. August. 